\title{
Os descendentes de imigrantes italianos rumo a terra dos seus antepassados
}

\author{
Sandra Nicoli ${ }^{1}$ \\ Mauro Augusto dos Santos ${ }^{2}$ \\ Sueli Siqueira ${ }^{3}$
}

Resumo: No Brasil, o projeto imigrantista a partir da segunda metade do século XIX, era baseado na pequena propriedade familiar. Minas Gerais foi destino secundário das famílias de imigrantes italianos. Nesse contexto, Itueta e Santa Rita do Itueto receberam, no início do século XX, famílias de imigrantes italianos oriundas do Norte da Itália, principalmente da região do Vêneto. Essas famílias promoveram uma nova configuração a esse território, inserindo novas técnicas de manejo da terra e novos costumes. A partir do final do século $\mathrm{XX}$, outro movimento migratório é realizado pelos descendentes das gerações mais novas, desta vez em direção à terra de seus avós, a Itália. Através de entrevistas em profundidade realizadas com os descendentes que emigraram para a Itália e retornaram ao Brasil, buscou-se compreender suas razões para emigrar, o cotidiano no destino e como perceberam sua italianidade na terra dos seus antepassados e, no retorno, qual a percepção de sua brasilidade. Em terras italianas, como lidaram com a situação de serem estrangeiros brasileiros e, ao mesmo tempo, descendentes de italianos. Os dados demonstram que se antes de emigrar consideravam-se descendentes, no retorno reafirmam sua identidade de brasileiros, pois no destino entendem que toda sua italianidade não é reflexiva.

Palavras-chave: Migração. Brasil. Itália. Identidade.

${ }^{1}$ Mestre em Gestão Integrada do Território pelo Programa de Pós-graduação Stricto Sensu da Universidade Vale do Rio Doce - Univale (2014). Possui graduação em Licenciatura Plena em História pela Universidade Vale do Rio Doce (2007).

${ }^{2}$ Doutor em Demografia pela Universidade Federal de Minas Gerais (2010). Possui graduação em Ciências Sociais, com ênfase em Sociologia, pela Universidade Federal de Minas Gerais (1997). Professor adjunto da Universidade Vale do Rio Doce (UNIVALE).

${ }^{3}$ Pós-doutorado no Centro de Investigação e Estudos de Sociologia do Instituto Universitário de Lisboa - CIES-IUL (2012). Doutorado em Sociologia e Política pela Universidade Federal de Minas Gerais (2006). Mestrado em Sociologia pela Universidade Federal de Minas Gerais (1998). Professora titular da Universidade Vale do Rio Doce. 
$|2|$

Os descendentes de imigrantes italianos...

\title{
The descendants of Italian immigrants towards to the land of their ancestors
}

\begin{abstract}
In Brazil, the immigrant project from the second half of the 19th century, was based on small family property. Minas Gerais was a secondary destination for Italian immigrant families. In this context, Itueta and Santa Rita do Itueto received, at the beginning of the 20th century, families of Italian immigrants from Northern Italy, mainly from the Veneto region. These families promoted a new configuration for this territory, introducing new techniques for land management and new customs. From the end of the twentieth century, another migratory movement was carried out by the descendants of the younger generations, this time towards the land of their grandparents, Italy. Through in-depth interviews with descendants who emigrated to Italy and returned to Brazil, we sought to understand their reasons for emigrating, their daily lives in the destination and how they perceived their Italianity in the land of their ancestors and, in return, what the perception of your Brazilianness. In Italian lands, how they dealt with the situation of being Brazilian foreigners and, at the same time, Italians descendants. The data show that if before emigrating they considered themselves descendants, in return they reaffirm their identity as Brazilians, because in the destination they understand that all their Italianity is not reflective.
\end{abstract}

Keywords: Migration. Brazil. Italy. Identity.

\section{Los descendientes de inmigrantes italianos hacia la tierra de sus antepasados}

Resumen: En Brasil, el proyecto de inmigrantes de la segunda mitad del siglo XIX se basaba en pequeñas propiedades familiares. Minas Gerais era un destino secundario para las familias inmigrantes italianas. En este contexto, Itueta y Santa Rita do Itueto recibieron, a principios del siglo $X X$, familias de inmigrantes italianos del norte de Italia, principalmente de la región del Véneto. Estas familias promovieron una nueva configuración para este territorio, introduciendo nuevas técnicas para el manejo de la tierra y nuevas costumbres. Desde finales del siglo XX, los descendientes de las generaciones más jóvenes llevaron a cabo otro movimiento migratorio, esta vez hacia la tierra de sus abuelos, Italia. A través de entrevistas en profundidad con descendientes que emigraron a Italia y regresaron a Brasil, buscamos comprender sus razones para emigrar, su vida cotidiana en el destino y cómo percibieron su italianaidad en la tierra de sus antepasados y, en el retorno, cuál es la percepción de tu brasilenidad. En tierras italianas, cómo lidiaron con la situación de ser extranjeros brasileños y, al mismo tiempo, descendientes de italianos. Los datos muestran que si antes de emigrar se consideraban descendientes, en el retorno reafirman su identidad como brasileños, porque en el destino entienden que toda su italianaidad no es reflexiva.

Palabras clave: Migración. Brasil. Italia. Identidad. 


\section{Introdução}

A imigração italiana para o Brasil teve início a partir dos anos de 1870, transformando-se em um fenômeno de massa, anos depois (TRENTO, 1989). Segundo Bassanezi (1995) a corrente imigratória italiana, no Brasil, revelou as seguintes especificidades: houve o predomínio da imigração familiar e a região do Vêneto foi a que mais forneceu imigrantes. O projeto imigratório familiar de colonização proposto à época era ditado pela necessidade de povoar e promover o desenvolvimento econômico conforme enfatizado por Dadalto (2009).

Monteiro (1994) menciona que o fluxo de estrangeiros de maior intensidade em Minas Gerais foi o de italianos. Mesmo que Minas Gerais não tenha tido grande destaque em relação à imigração europeia, os italianos se sobressaíram nesse estado. Ressalta-se que Minas Gerais foi um destino secundário da colonização italiana no Brasil conforme afirmam (TRENTO, 1989; CENNI, 1994).

Nesse ponto, é interessante mencionar que segundo Anastásia (1990), indiscutivelmente, foi a corrente italiana preponderante na imigração para Minas Gerais. Entre 1894 e 1901, dos 52.582 imigrantes que entraram no Estado, 47.096 (89,5\%) eram italianos.

Propondo percorrer a imaginária ponte que liga a Itália e Minas Gerais, Souza (2019) argumenta que cerca de 70 mil italianos vieram, para Minas, em busca de um sonho. Atualmente, segundo Souza (2019), cerca de 7,5\% da população mineira é descendente de famílias de imigrantes italianos.

Destaca-se que o Vale do Rio Doce fez parte da estratégia governamental de colonização, tornando-se a última região mineira a ser colonizada (ESPINDOLA, 2005). E foi nessa circunstância que os municípios de Itueta e Santa Rita do Itueto, no início do século $\mathrm{XX}$, foram palco da chegada de migrantes de outras regiões do Brasil e de outras nacionalidades, com destaque para os italianos, pomeranos, alemães, portugueses e espanhóis. A presença de imigrantes e descendentes de origem italiana se tornou marcante, 
$|4|$

Os descendentes de imigrantes italianos...

ao longo dos anos, em relação às outras nacionalidades (NICOLI, 2014).

Situado na região geográfica imediata de AimorésResplendor, o município de Itueta, com uma área territorial de $452,7 \mathrm{Km}^{2}$, possuía uma população, segundo os dados do Censo Demográfico de 2010 de 5.830 habitantes, sendo que 56,6\% deles residiam na zona urbana do município. A população estimada em 2020 para o município foi de 6.083 habitantes $^{4}$.

Itueta é um município tipicamente rural, prevalecendo propriedades de caráter familiar. Dentre as atividades econômicas mais significativas destacam-se o cultivo de café, milho, feijão, cana-de-açúcar, mandioca, além da criação de gado leiteiro e de corte, e com menor expressão, a suinocultura. Outra atividade econômica que se pode destacar é a extração de madeira (REZENDE; ÁLVARES, 2009).

Santa Rita do Itueto também é um município tipicamente rural, predominando propriedades de caráter familiar. A produção de café e a pecuária leiteira constituem as principais atividades econômicas do município. Como culturas tradicionais de subsistência também são cultivados o milho, o feijão e o arroz, que constituem a base alimentar das famílias. A fruticultura é outra atividade que vem ocupando destaque em Santa Rita do Itueto, como alternativa de diversificação agrícola e busca de novas opções de renda para o produtor rural (INFORMATIVO da Prefeitura Municipal de Santa Rita do Itueto, 2006).

Também situado na região geográfica imediata de Aimorés -Resplendor, o município de Santa Rita do Itueto possuía uma população de 5.697 habitantes dispersa por uma área territorial de 485,1 Km² - segundo os dados do Censo Demográfico de 2010 -, sendo que desses, apenas 40,5\% residiam na zona urbana. Sua população estimada para 2020 era de 5.457 habitantes $^{5}$.

${ }^{4}$ IBGE. Diretoria de Pesquisas - DPE - Coordenação de População e Indicadores Sociais - COPIS. Estimativas da população residente no Brasil e Unidades da Federação com data de referência em 1ํํㄹ de julho de 2020.

${ }^{5}$ IBGE. Diretoria de Pesquisas - DPE - Coordenação de População e Indicadores 
Os migrantes italianos que chegaram aos municípios de Itueta e Santa Rita do Itueto eram, em sua maioria, famílias camponesas oriundas do Norte da Itália, principalmente da região do Vêneto. Eles se dirigiram primeiramente para as regiões de Alfredo Chaves e Castelo no Espírito Santo, vindo, posteriormente, para os municípios mineiros localizados na divisa interestadual com esse estado. A chegada de diversas famílias de migrantes italianos e seus descendentes promoveu uma nova configuração a esse território, inserindo novas técnicas de manejo da terra, novos costumes e valores (NICOLI, 2014).

Sociais - COPIS. Estimativas da população residente no Brasil e Unidades da

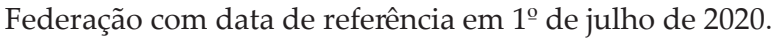


$|6|$

Os descendentes de imigrantes italianos...

Figura 01: Municípios da Região Imediata de AimorésResplendor, Minas Gerais, Brasil.

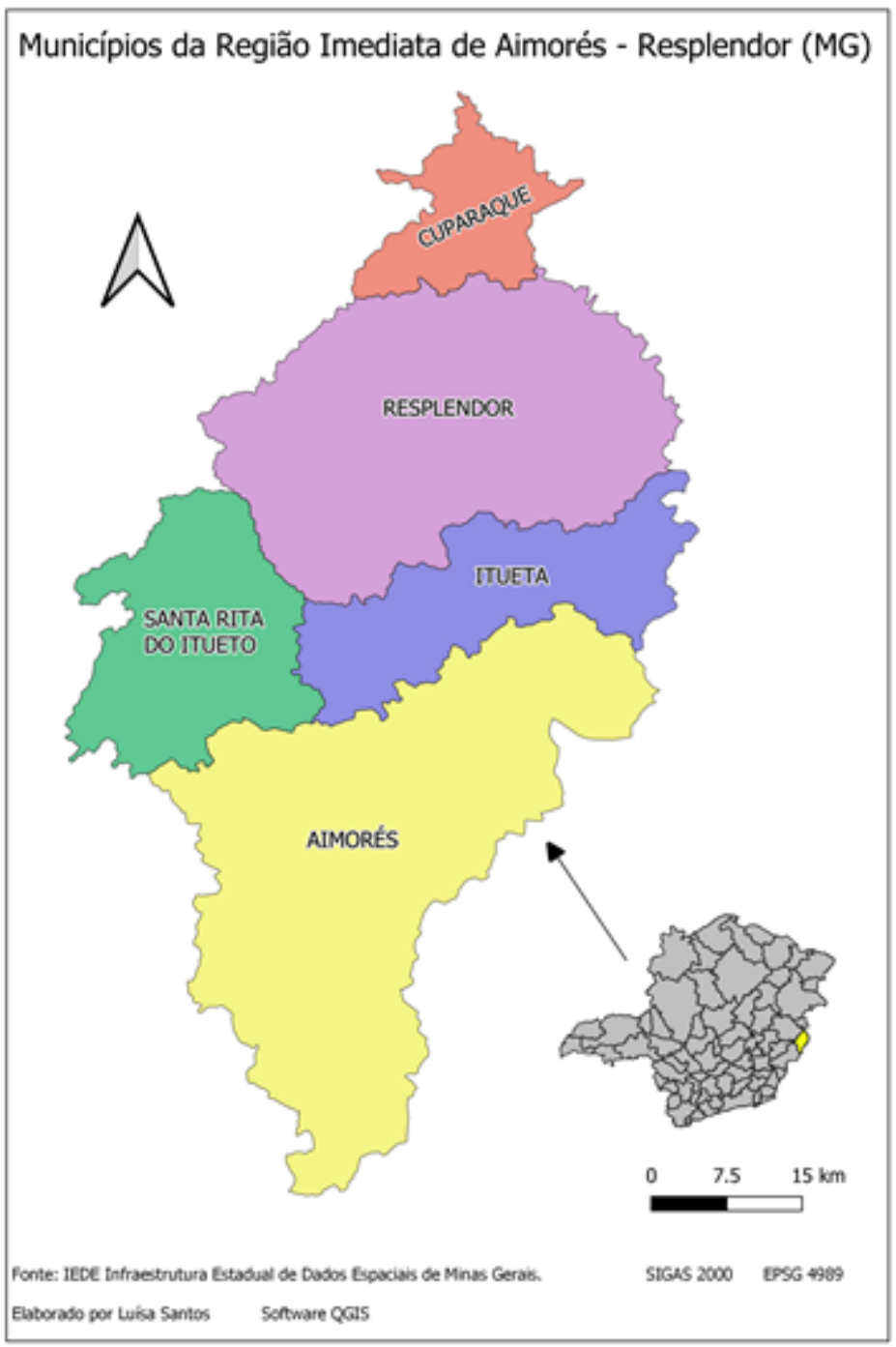

Fonte: IEDE. Infraestrutura Estadual de dados espaciais de Minas Gerais 
Salienta-se que com o passar dos anos e com o fracionamento das terras devido à herança dividida entre os muitos filhos dos migrantes italianos, a sobrevivência dos descendentes das gerações mais novas se tornou cada vez mais difícil, pois não havia mais a perspectiva de continuar tirando o sustento somente da terra. Essa situação, atrelada à procura pela independência financeira e pela melhoria da qualidade de vida dentro dos novos padrões de consumo da atual sociedade, acabou gerando um cenário que propiciou a emigração de membros das gerações mais novas (NICOLI; GENOVEZ; SIQUEIRA, 2013).

Este trabalho abordará o movimento migratório internacional. No presente estudo, vamos analisar as narrativas dos descendentes das famílias de migrantes italianos residentes nas terras mineiras de Itueta e Santa Rita do Itueto que emigraram para a terra dos seus nonos (avós), a partir do final do século XX.

No que tange a análise das entrevistas em profundidade, considerou-se a experiência migratória dos descendentes emigrantes a partir das narrativas elaboradas durante a coleta de dados. Ao elaborar a narrativa do processo migratório desde a decisão de partida até a chegada ao destino, diversos processos de subjetivação vêm à tona. Conforme Nicoli; Genovez; Siqueira (2013, p. 373), “a narrativa, nesse sentido, pode ser compreendida como um momento de elaboração da experiência do deslocamento/ desenraizamento através da fala [...] quem narra, reconfigura os eventos e os redimensiona no tempo e espaço".

Destaca-se que, como metodologia, foi utilizada a técnica da entrevista em profundidade e, para identificação dos sujeitos, utilizou-se a técnica "bola de neve" em que um entrevistado vai informando sobre outro(os) sujeito(os) que se adequem ao perfil pesquisado. Para a elaboração desse artigo, foram utilizadas sete (07) entrevistas em profundidade colhidas durante o trabalho de campo, realizado entre os meses de setembro de 2011 a agosto de 2012. 
$|8|$

Os descendentes de imigrantes italianos...

\section{Quadro 01: Principais características dos descendentes entrevistados. \\ Fonte: Pesquisa de campo, 2011/2012.}

\begin{tabular}{|c|c|c|c|c|c|}
\hline $\begin{array}{l}\text { Entrevis- } \\
\text { tado }\end{array}$ & Idade & Sexo & $\begin{array}{l}\text { Grau de } \\
\text { instrução }\end{array}$ & $\begin{array}{l}\text { Atividade/Renda } \\
\text { antes de emigrar }\end{array}$ & Investimento \\
\hline J. B. Magri & 35 & Masc. & $\begin{array}{l}\text { Ensino } \\
\text { Médio Com- } \\
\text { pleto }\end{array}$ & $\begin{array}{l}\text { Trabalhava com o } \\
\text { pai na proprieda- } \\
\text { de rural }\end{array}$ & $\begin{array}{c}\text { Ampliação da lavoura/ } \\
\text { melhoramento do } \\
\text { solo/ poupança }\end{array}$ \\
\hline $\begin{array}{l}\text { E. Mighio- } \\
\text { rin }\end{array}$ & 39 & Masc. & $\begin{array}{l}\text { Ensino } \\
\text { Médio In- } \\
\text { completo }\end{array}$ & Empregado/CLT & $\begin{array}{l}\text { Investimento em co- } \\
\text { mércio na área urbana } \\
\text { / poupança }\end{array}$ \\
\hline $\begin{array}{c}\text { M. Vaz- } \\
\text { zoler }\end{array}$ & 36 & Fem. & $\begin{array}{l}\text { Ensino Fun- } \\
\text { damental } \\
\text { Incompleto }\end{array}$ & $\begin{array}{l}\text { Serviços domésti- } \\
\text { cos na área rural }\end{array}$ & $\begin{array}{c}\text { Construção da casa } \\
\text { na área rural /compra } \\
\text { de propriedade rural / } \\
\text { poupança }\end{array}$ \\
\hline M. Fazzolo & 31 & Masc. & $\begin{array}{l}\text { Ensino } \\
\text { Médio Com- } \\
\text { pleto }\end{array}$ & $\begin{array}{c}\text { Trabalhava com o } \\
\text { pai na proprieda- } \\
\text { de rural }\end{array}$ & $\begin{array}{c}\text { Compra de um cami- } \\
\text { nhão para trabalho/ } \\
\text { poupança }\end{array}$ \\
\hline P. Magri & 23 & Masc. & $\begin{array}{l}\text { Ensino } \\
\text { Médio Com- } \\
\text { pleto }\end{array}$ & $\begin{array}{c}\text { Trabalhava com o } \\
\text { pai na proprieda- } \\
\text { de rural }\end{array}$ & Poupança \\
\hline $\begin{array}{l}\text { A. Casa- } \\
\text { grande }\end{array}$ & 32 & Fem. & $\begin{array}{l}\text { Ensino } \\
\text { Médio Com- } \\
\text { pleto }\end{array}$ & Trabalhadora/CLT & $\begin{array}{c}\text { Investimentos em imó- } \\
\text { veis na área urbana } \\
\text { e rural }\end{array}$ \\
\hline A. Baldon & 50 & Masc. & $\begin{array}{l}\text { Ensino Fun- } \\
\text { damental } \\
\text { Completo }\end{array}$ & $\begin{array}{l}\text { Trabalhava com o } \\
\text { pai e os irmãos na } \\
\text { propriedade rural }\end{array}$ & $\begin{array}{c}\text { Construção da casa na } \\
\text { área rural /investimen- } \\
\text { tos em café/ compra } \\
\text { de propriedade rural/ } \\
\text { poupança/compra de } \\
\text { imóvel na Itália }\end{array}$ \\
\hline
\end{tabular}

Fonte: Elaboração própria.

\section{Rumo à terra dos nonos}

A migração é um componente da dinâmica demográfica que responde mais velozmente a variações na conjuntura socioeconômica. Sua concretização depende de fatores estruturais e conjunturais, além de passar pela decisão individual e pela 
avaliação de riscos e retornos que o empreendimento pode vir a realizar (SANTOS; BARBIERE, 2012).

Nesse sentido, desde a segunda metade dos anos de 1980, há um intenso fluxo migratório internacional no Vale do Rio Doce, marcadamente direcionado para os Estados Unidos da América - EUA. Mesmo que no decorrer do tempo ocorra uma mudança nos planos iniciais, a maioria desses emigrantes tem, como projeto, retornar e investir na sua região de origem, objetivando melhorar sua condição socioeconômica, conforme ressalta Siqueira (2009).

Inicialmente os descendentes de italianos de Itueta e Santa Rita do Itueto seguiram o mesmo fluxo, emigrando para os Estados Unidos da América. Porém, o documento de dupla cidadania, que possibilita a entrada no território norte-americano sem o visto, não autoriza a realização de atividade laboral remunerada. Portanto, ao exercer essas atividades, esses emigrantes tornavam-se

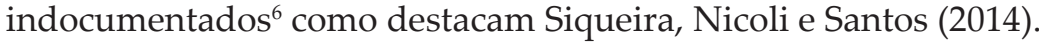

O atentado das torres gêmeas em setembro de 2001 provocou o acirramento da fiscalização da Imigração norte-americana, tornando a entrada nos Estados Unidos mais difícil. Esse fato provocou o redirecionamento e a intensificação dos fluxos para países da Europa como Portugal, Espanha e Itália, embora os Estados Unidos tenham continuado a ser o destino preferido pelos emigrantes brasileiros. Os migrantes de Itueta e Santa Rita do Itueto passaram a se deslocar para o norte da Itália, a mesma região de origem dos seus antepassados. É certo que o documento de dupla cidadania é um fator determinante para escolherem emigrar para a Itália, pois através dele conseguem trabalhar e viver documentados no país, ficando livres dos constrangimentos pelos quais passam os migrantes indocumentados, como é o caso dos que emigram para os Estados Unidos da América. Outro fator que os levaram a essa escolha é o desejo de conhecer a Itália das histórias ouvidas desde a infância, contadas pelos seus pais e nonos. Eles cresceram ouvindo que eram italianos nascidos no Brasil, portanto, diferente

${ }^{6}$ Consideramos o termo "ilegal" inapropriado para se referir ao emigrante, por essa razão utilizamos o termo indocumentado. 
dos "brasileiros"7 (NICOLI, 2014). Como ressalta Santos e Zanini (2012, p. 06) "é a ideia de continuidade nacional, de manutenção da cultura da pátria-mãe, mesmo no caso de imigrantes de mais de um século, que permite pensar o projeto migratório como uma imigração de retorno".

As histórias contadas e recontadas pelos pais e nonos narravam a longa viagem transatlântica, a chegada em terras estrangeiras (brasileiras), de como foram difíceis a instalação em locais ainda poucos habitados e cobertos pelas florestas, as construções das casas para abrigo e a formação das lavouras de café. Essas histórias sempre reafirmam o protagonismo das famílias italianas em meio aos tempos difíceis de chegada e instalação nas novas terras. Demonstram, também, que foram agentes de sua própria história, no sentido de construir seu próprio espaço e manter, de certa maneira, os traços culturais da sociedade de onde vieram (NICOLI, 2014).

Essas histórias, contadas e recontadas por gerações, possibilitam a continuidade de uma noção de pertencimento, traduzida numa identidade étnica: à origem italiana a partir da ideia de italianidade construída e reconstruída pelos antepassados e transmitida aos descendentes através das histórias.

Nesse contexto, é fundamental enfatizar que todos os grupos sociais desenvolvem uma memória do seu próprio passado coletivo, e essa memória é fundamental na manutenção de um sentimento de identidade e pertença que permite identificar o grupo e distingui-lo dos demais (PERALTA, 2007).

Fernandes e Rigotti (2009) mencionam que a emigração de descendentes para a Itália, apresenta contornos diferentes em relação a outros destinos da Europa. A história da Itália, as relações estabelecidas com o Brasil no passado e as facilidades oferecidas pela legislação italiana para a obtenção da segunda cidadania por

\footnotetext{
${ }^{7}$ Enfatiza-se que na região estudada, os descendentes de imigrantes italianos se consideram "italianos" e os não descendentes são considerados "brasileiros". É comum a expressão: "nós italianos e os brasileiros".
} 
descendentes de imigrantes ${ }^{8}$ que chegaram às terras brasileiras no final do século XIX e início do XX, são fatores que contribuem para esta diferença e devem ser levados em consideração.

Os italianos que migraram para o Brasil, carregavam consigo o desejo de recriar em solo brasileiro uma nova Itália. Ou seja, um espaço relacional de italianidade que se constrói ao longo do tempo numa relação identitária ligando a comunidade ao espaço vivido/ apropriado. Nesse sentido, vieram para ficar e aqui constituir ou manter suas famílias em melhores condições do que na sua terra natal. Diferentemente, os descendentes dessas famílias emigraram com o principal objetivo de trabalhar, fazer poupança, investir e retornar para o local de origem (NICOLI, 2014). Os entrevistados nesse estudo são, em sua maioria, pessoas na faixa etária de 23 a 50 anos, com oito anos de escolaridade em média, majoritariamente do sexo masculino, que haviam permanecido entre três a oito anos no destino e originários principalmente da zona rural de seus municípios de origem.

\section{3. "Extra Comuni" na terra dos antepassados}

O território formado e apropriado a partir das relações sociais em Itueta e Santa Rita do Itueto, ou seja, o território "italianizado" deixou marcas e histórias por gerações nestas terras mineiras. De tal modo que, os descendentes que emigraram continham informações de uma Itália ainda do século XIX. Por isso, ao chegarem a terras italianas, todas as informações que guardavam na memória foram desconstruídas ao perceberem que estavam em uma Itália totalmente diferente da que traziam no seu imaginário (NICOLI, 2014).

Enfatiza-se que as marcas identitárias e histórias fixadas nas terras mineiras através da territorialização das famílias de origem

\footnotetext{
${ }^{8} \mathrm{Na}$ Europa, somente a Itália permite a obtenção da nacionalidade por bisnetos de imigrantes e, em algumas situações, mais além dessa ascendência familiar. A facilidade em se conseguir o documento de dupla cidadania tem atraído muitos descendentes (FERNANDES; RIGOTTI, 2009).
} 
italiana, os significados, os sentidos e os valores atribuídos a esse espaço, e que constituem sua identidade, não existem desde sempre nem são inerentes à natureza. São inventados e reinventados a cada vivência e momento desde a chegada em terras brasileiras, mais especificamente mineiras.

Nessa perspectiva, Saquet (2010) evidencia que no território as relações sociais se materializam e se reproduzem. Assim, a identidade é um componente fundamental na constituição do território, resultando da combinação dos processos histórico e relacional. Segundo Haesbaert (1999, p. 172), “a identidade territorial é uma identidade social definida fundamentalmente através do território, ou seja, dentro de uma relação de apropriação".

\begin{abstract}
Os italianos antigos daqui [Itueta e Santa Rita do Itueto] também preservam muita coisa e destacam que é de italiano. Mas nós mais novos não estamos preservando tanto quanto eles. Lá na Itália eu percebi isso também, porém com os mais idosos, agora com os mais novos, estão muito pior que nós, de italianos eles num têm nada. (P. Magri', 23 anos, Santa Rita do Itueto).
\end{abstract}

Beneduzi (2014) ressalta esse diferencial entre o destino idealizado pelo migrante com base principalmente nos relatos de seus pais, avós e outros parentes e a realidade encontrada. Segundo o autor, "o elemento-chave desses trânsitos é a confirmação (ou não) entre a Itália imaginada e a de fato encontrada, fosse ela o país dos ancestrais, a comunidade idealizada" (BENEDUZI, 2014, p. 93).

${ }^{9}$ Destaca-se que a identificação dos sujeitos será feita pela letra inicial do nome e pelo sobrenome de descendência italiana, a idade e o local/região de residência. Desta forma, estaremos preservando o anonimato do entrevistado (a) e demonstrando alguns sobrenomes de origem italiana residentes nas localidades em estudo. Enfatiza-se que apenas uma entrevistada estava a passeio no Brasil, por isso, será colocada a região de residência na Itália. 
[Informações atuais da Itália] Pouco. Por televisão e mais com amigos, né. No caso amigos que já estavam lá. De uma Itália de agora. [a informação mais concretaantepassados] Da Itália que eles saíram, a informação que eu tinha, que eu sei, que eu sempre soube, deles falar, é as histórias deles, né. Que eles comentavam, era uma Itália que não estava num período muito bom. Tanto que eles vieram pra cá, saíram de lá, procurando alguma coisa melhor aqui, né (M. Fazzolo, 31 anos, Itueta).

Os descendentes emigrantes chegam à Itália com o documento de dupla cidadania, confiando estar nas mesmas condições do italiano nativo. Porém, em suas narrativas, confirmam a desilusão em relação ao tratamento recebido como cidadãos italianos, pois o documento de cidadania permite a inserção dessas pessoas de forma legal no mercado de trabalho, mas não na sociedade italiana. Eles, independente de gênero, como a maior parte dos estrangeiros, só conseguem se inserir no mercado de trabalho secundário (NICOLI; SIQUEIRA, 2012). É o que aponta os relatos destacados a seguir.

Construção civil. [...], pedreiro. [...], acabei de aprender lá. [...] Reforma de banheiro, piso, azulejo esse ramo aí. (A. Baldon, 50 anos, Santa Rita do Itueto).

Limpeza. [...], limpeza de portaria de prédio. Eu trabalhava de porteiro no prédio. Limpando e cuidando da portaria. (M. Vazzoler, 36 anos, Santa Rita do Itueto).

Em relação ao documento de dupla cidadania, Tedesco (2010) ressalta que ele é apenas um instrumento que permite o acesso do migrante ao mercado de trabalho, atendendo aos interesses de ambos os lados (imigrantes e país receptor), não havendo, entretanto, qualquer projeto relacionado ao envolvimento cultural desse indivíduo. O mesmo é enfatizado por Zanini e Herédia (2014), quando afirmam que, 
$|14|$

Os descendentes de imigrantes italianos...

as razões para concretizar o projeto migratório foram muitas e que todas elas estavam interligadas a questões econômicas, culturais, afetivas, marcadas pela presença simbólica das representações sociais e pelo cruzamento com trajetórias de vida específicas, para as quais a emigração rumo a Itália constituiu uma opção viável de melhoria das condições de vida. Regidos por um imaginário construído acerca da terra dos antepassados, estes migrantes se depararam com situações bastante complexa, desafiados por contingências que revelam a frágil situação do migrante em terra estrangeira, mesmo quando portador da cidadania (ZANINI; HERÉDIA, 2014, p. 131-132).

A cultura vivenciada em seus locais de origem a partir das canções, da culinária, das festas típicas italianas e das histórias revividas a partir dos relatos de seus antepassados - contadas no seu dialeto próprio -, não lhes ofereceu nenhuma identidade italiana que promovesse a inserção na sociedade de destino. Ao contrário, lá eles se perceberam estrangeiros: ou seja, brasileiros. Assim, toda identidade italiana que os definia no local de origem foi desmontada, ao se perceberem como qualquer outro estrangeiro no país que acreditavam fazer parte de sua identidade (NICOLI; SIQUEIRA, 2012).

Segundo Tedesco (2010, p. 30), o descendente na Itália reavalia e ressignifica o seu pertencimento aquela cultura, passando a perceber-se apenas "como mercadoria, como força de trabalho pelas várias expressões do capital na sociedade de destino". Dessa forma ele encontraria barreiras e facilidades que surgiriam de acordo com os interesses locais.

Também Santos e Zanini (2012) ressaltam o sentimento desses emigrantes de se sentirem estrangeiros vivenciado por muitos descendentes de italianos que emigraram para a Itália no final do século XX e início do XXI. O relato apresentado, a seguir, deixa claro essa experiência vivenciada pelos descendentes emigrantes. 
Aqui nós somos considerados italianos. Somos vistos como diferentes. Não tanto atualmente, mas somos diferenciados dos que não tem origem italiana. Quando a gente chega lá descobre que somos mais parecidos com os brasileiros do que com os italianos de lá. Eles nos consideram e nós nos sentimos estrangeiros. Como eles mesmos sempre falam: "extra comuni". Nós somos de fora da sociedade deles. (P. Magri, 23 anos, Santa Rita do Itueto).

De acordo com Sayad (1998), a cultura se refere a um conjunto de referenciais que permitem a cada membro de uma sociedade movimentar-se, expressar-se, pensar, amar, trabalhar, evitando o medo e se protegendo do desconhecido. Os migrantes brasileiros, por serem descendentes de italianos, se sentem ligados a cultura italiana. $\mathrm{O}$ impacto de se sentirem estrangeiros no país que, na concepção deles deveria acolhê-los, é algo que marca profundamente esses sujeitos. Como ressalta Tedesco (2010, p. 2728), "a noção de extracomunitário, sua lógica e efetivação cotidiana e prática no mundo do trabalho, transcende esses vínculos históricos e de sangue".

Foi muito grande assim, foi muito grande, muito grande. Que você chegar num país que sua família, seu sangue tá ali né, nós somos descendentes de italiano. Então nosso sangue é italiano, mesmo que nós nascemos no Brasil. Aquilo dos nossos avós, no caso, e tudo fica no sangue. Eu tinha uma ideia assim muito forte, muito forte mesmo que era tudo certinho né, $[\ldots]$, mas, $[\ldots]$ a gente tem impacto assim, que não é aquilo que a gente pensava. [...]. Muita diferença! (E. Mighiorin, 39 anos, Santa Rita do Itueto).

Nesse sentido, os descendentes das famílias de imigrantes italianos se veem como parte de um processo histórico compartilhado. As histórias da imigração italiana para o Brasil e, especialmente para o Espírito Santo e Minas Gerais, são contadas e recontadas com o objetivo de marcar sua grandeza. Tais narrativas 
$|16|$

Os descendentes de imigrantes italianos...

permitem a continuidade de uma noção de pertencimento fundamentada no mundo de origem italiana. Na trajetória migratória, a ideia de italianidade construída pelos nonos e transmitida aos descendentes é desconstruída, pois ao chegarem à Itália percebemse brasileiros (SANTOS; ZANINI, 2012; NICOLI, 2015).

Mesmo que somos descendentes de italianos, temos o documento de cidadania concedido pelo Consulado da Itália no Brasil, lá nós somos vistos como estrangeiros, latinos, brasileiros. Nada do que nos define aqui no nosso local como italianos existe lá [Itália]. [...]. Descobrimos que somos brasileiros mais lá do que aqui [Brasil]. Nem língua, nem comida, nem costumes nos ajudam a ser reconhecidos como italianos como aqui no nosso local. [...]. Eles [italianos] compreendem que somos descendentes e temos direitos e deveres como italianos, mas não nos consideram como tais (J. B. Magri, 35 anos, Santa Rita do Itueto).

A nossa terra, a nossa vida, o nosso território é aqui! É no Brasil. Somos descendentes de italianos, mas nascemos no Brasil. (J. B. Magri, 35 anos, Santa Rita do Itueto).

Em relação aos descendentes que emigraram para a Itália, Zanini e Herédia (2014) também evidenciam o sentimento de se sentirem estrangeiros nesse país.

Após o processo migratório e todas as complexidades nele envolvidas, não se percebem da mesma forma, nem em relação ao Brasil e nem em relação a suas existências. [...]. Por detrás de cada "sonho", [...], estava a intenção de que a Itália, não mais a madrasta que havia expulsado seus antepassados, agora os receberia de braços abertos, o que infelizmente não aconteceu. [...], o mito foi substituído pela ideia de que a verdadeira pátria está no lugar em que nasceram (ZANINI; HERÉDIA, 2014, p. 140-141). 
Ao chegarem às localidades mineiras de Itueta e Santa Rita do Itueto, os emigrantes retornados demonstram que estar na terra dos nonos os fez ver que ela não era o que imaginaram ao sair de Minas Gerais e do Brasil. A Itália da memória dos pais, tios, avôs e bisavós ficou num passado distante - uma Itália ainda do século XIX, impregnada nas memórias. Na atual Itália, não está presente a Itália de suas memórias. Em terras italianas descobrem que são identificados como estrangeiros - nesse caso, como brasileiros - e não como descendentes de italianos, como são vistos e como se sentem nos locais de origem (NICOLI, 2014).

No que se refere a produção social da memória, é fundamental mencionar que as narrativas se constituem importantes instrumentos de preservação e transmissão das heranças identitárias. Narrativas sob a forma de registros orais ou escritos são caracterizadas pelo movimento peculiar à arte de contar, de traduzir em palavras as reminiscências da memória e a consciência da memória no tempo, conforme afirma Delgado (2005).

Para Halbwachs (1990), a memória é entendida como um fenômeno coletivo e social, ou seja, como um fenômeno construído coletivamente e submetido a flutuações, transformações e mudanças constantes. Nessa acepção, “a memória é um fenômeno construído social e individualmente, quando se trata de memória herdada, podemos também dizer que há uma ligação muito estreita entre a memória e o sentimento de identidade" (Pollak, 1992, p. 205).

Assim, pode-se enfatizar que os descendentes emigrantes reconstroem suas narrativas selecionando, recortando, reconstruindo suas memórias em função das questões que lhes são colocadas no presente.

\section{As redes estabelecidas na terra dos nonos}

Enfatiza-se que a rede de ajuda e informações que se aperfeiçoou durante a chegada das famílias de migrantes italianos a Itueta e Santa Rita do Itueto, no início do século XX, continua sendo observada entre os descendentes que emigram para a 
$|18|$

Os descendentes de imigrantes italianos...

Itália. No destino, já é possível perceber a formação de uma rede de relações entre os descendentes, com formas e características diferentes dos primeiros migrantes, porém com a mesma intenção de minimizar os riscos e sofrimentos (NICOLI, 2014).

Massey et al (1993) ressaltam que o fenômeno da migração internacional pode ser também explicado no estabelecimento de redes sociais. As redes de migrantes são conjuntos de laços interpessoais que ligam migrantes, migrantes anteriores e não migrantes. Portanto, a teoria das redes compreende o fenômeno da migração internacional a partir de um conjunto de conexões estabelecidas pelas relações sociais tanto na origem quanto no destino.

Tenho um irmão que mora comigo e o meu cunhado e sua esposa e tenho o meu primo. [...] são também descendentes. Vamos dizer, todos passavam na minha casa, o ponto de apoio foi a nossa casa depois a gente ia dividindo aí cada um ia dividindo. [...], inclusive a gente se reúne, não sempre, a gente se reúne em datas comemorativas, como aniversário ou datas festivas como natal, ano novo a gente se reúne faz churrasco, às vezes até dança, às vezes vai em um parque a passeio. Tem bares tem restaurante brasileiro é onde tem um maior fluxo de brasileiros e se reúne assim, só quando vem o frio que vai todo mundo para a toquinha e é mais difícil. (A. Casagrande, 32 anos, Itueta/Toscana).

Olha, era independente se era dessa região ou não, talvez era um amigo do amigo dele que ele fez lá. Então era uma corrente assim, era um ajudando o outro. Tenho um amigo que tá precisando disso se um tá podendo ajudar o outro ajuda, o outro tá chegando... (M. Vazzoler, 36 anos, Santa Rita do Itueto).

Tilly (1990) ressalta a importância das redes sociais na articulação dos processos migratórios, enfatizando a solidariedade no interior dos grupos migrantes como uma das características que configuram e sustentam as redes sociais. Assim, as redes sociais 
emergem em decorrência do próprio desenvolvimento do processo migratório e das conexões que passam a ser estabelecidas.

Também Siqueira (2009) ressalta a importância das redes.

As redes fornecem informações, indicam meios que auxiliam o processo de migração e atenuam as dificuldades no país de destino. A migração internacional pressupõe ir ao encontro de uma sociedade, geralmente com língua, costumes e valores diferentes. Significa um empreendimento de muitos riscos. Riscos estes que são amenizados por intermédio das redes sociais. Além de facilitadoras na concretização do projeto de migrar, as redes dão novas configurações ao meio no qual se estabelecem. Junto com os projetos pessoais ou coletivos o imigrante leva também sua identidade étnica, suas relações de parentesco, suas identidades de gênero, enfim, um background cultural que vai consigo. Seus valores e costumes dão nova configuração à sociedade de destino (SIQUEIRA, 2009, p. 46).

Mediante as narrativas dos descendentes emigrantes, é possível destacar que as redes estabelecidas desde a terra de partida e na terra de chegada são com pessoas do Brasil. Portanto, a inserção na sociedade italiana não ocorre como imaginavam antes de emigrarem.

Abdelmalek Sayad (2010) em relação ao conceito de dupla ausência, descreveu a situação de várias gerações de emigrantes submetidas à situação de dupla ausência: já não estão no seu país de origem, perderam as ligações importantes e, ao mesmo tempo, não têm direitos como os cidadãos no país que escolheram viver. Assim, esse sentimento de ausência tanto como emigrado quanto imigrado, configura o que Sayad denomina em seus escritos de doble ausencia. Tal conceito refere-se ao sentimento do migrante em relação à terra natal, à qual não se sente mais pertencente e, ao mesmo tempo, o sentimento de não pertencimento à terra receptora. 
$|20|$

Os descendentes de imigrantes italianos...

Esse é um dos numerosos paradoxos da imigração: ausente onde está presente e presente onde está ausente. Duplamente presente - efetivamente aqui e ficticiamente lá - e duplamente ausente - ficticiamente aqui e efetivamente lá - o imigrante teria uma vida dupla, que ultrapassa e que é diversa da oposição tradicional entre vida pública e vida íntima: uma vida presente, banal, cotidiana, vida que pesa e enreda, vida segunda, ao mesmo tempo cronológica e essencialmente secundária; uma vida ausente, figurada ou imaginada, rememorada, uma vida que foi primeira cronologicamente e que permaneceu primeira, essencial, afetiva e efetivamente, e que, sem dúvida, voltará a sê-lo um dia (Sayad, 2000, p. 20).

Conforme Fernandes e Rigotti (2009), as redes migratórias vinculam imigrantes, emigrantes retornados ou candidatos à migração com parentes, amigos ou compatriotas. Assim, as redes podem ser vistas como um capital social que irá permitir o acesso a informações, indicações e bens de valor econômico.

Boyd (1989) argumenta que as redes sociais são fundamentais para a compreensão dos movimentos migratórios no que se refere ao início e sustentação dos fluxos. No caso da emigração da região estudada, Siqueira (2018) destaca a importância das redes para a configuração e permanência de um fluxo migratório. Essas redes além de interligar origem e destino, fornecendo informações importantes para a mobilidade, são fundamentais para a organização da partida e para minimizar os constrangimentos na terra dos nonos, pois, disponibilizam mecanismos de recepção, organização da vida social e laboral.

\section{Considerações finais}

Diante dos dados coletados é possível enfatizar que esses dois fluxos, dos imigrantes italianos vindo para o Brasil em busca de sobrevivência e atualmente de seus descendentes indo em direção inversa se distanciam não apenas no tempo, mas também 
na natureza, perfil do emigrante e projeto de emigração. Enquanto as famílias italianas chegaram às terras brasileiras com objetivo de nela permanecerem, os descendentes emigram para a Itália com o projeto de retornar para o Brasil. Ressalta-se, também, que a primeira emigração era familiar, enquanto a emigração dos descendentes é individual.

As famílias de imigrantes italianos ao chegarem às terras brasileiras, buscavam manter sua italianidade através da reconstrução de hábitos e costumes, das festas e da ideia transmitida para os seus descendentes de que ser descendente é ser diferente dos brasileiros. Isso porque tinham um modo de ser diferente no trato da terra, na relação com os outros e nos costumes, estando essa percepção presente na expressão sempre repetida "nós italianos e os brasileiros". Diferentemente, os descendentes que fazem o movimento migratório inverso ao dos seus antepassados, ao chegarem às terras italianas percebem-se brasileiros, pois não encontram a Itália reconstruída pela memória transmitida por seus nonos.

A emigração dos descendentes para a Itália tem como objetivo a busca da independência financeira e a melhoria da qualidade de vida dentro dos novos padrões de consumo da atual sociedade. O documento de dupla cidadania e a possibilidade de conhecer a Itália das histórias ouvidas desde a infância são fatores determinantes pela escolha do destino. No entanto, a cultura vivenciada, na origem, não garantiu nenhuma identidade italiana que promovesse a inserção, desses descendentes, na sociedade de destino. Ao retornarem para o Brasil, mais especificamente para Minas Gerais, esses emigrantes, que no processo migratório reelaboraram sua noção de pertencimento numa interação entre presente e passado, reafirmam sua identidade de brasileiros, pois no destino entendem que toda sua italianidade não é reflexiva. 
$|22|$

Os descendentes de imigrantes italianos...

\section{Referências}

ANASTÁSIA, Carla Maria Junho. A imigração italiana em Minas Gerais (1896-1915). In: BONI, Luís Alberto de (Org.). A presença italiana no Brasil. Porto Alegre: Escola Superior de Teologia; Torino: Fondazione Giovanni Agnelli, 1990. 2 vol.

BASSANEZI, Maria Silvia Casagrande Beozzo. Imigrações Internacionais no Brasil: um panorama histórico. In: PATARRA, Neide Lopes. (Org) Emigração e Imigração internacionais no Brasil contemporâneo. São Paulo: FNUAP, 1995, v. 1, p. 3-35.

BENEDUZI, Luís Fernando. O que significa ser ítalo-brasileiro na Itália? Entre experiências e expectativas, três leituras. In: ASSIS, Gláucia de Oliveira; BENEDUZI, Luís Fernando (Org.). Os pequenos pontos de partida: novos e(i)migrantes rumo à Itália no século XXI. 1ed. Curitiba/PR: CRV, 2014, v. 1, p. 83-110.

BOYD, Monica. Family and personal networks in international migration: recent developments and new agenda. International Migration Review. S. I. v. 23, n. 3,. p. 638-670, 1989.

CENNI, Franco. Italianos no Brasil: "andiamo in'Merica...". Edusp, 1994.

DADALTO, Maria Cristina. A imigração Tece a Cidade - polo industrial de Colatina. Vitória: Cultural \& Edições Tertúlia, 2009.

DELGADO. Lucília de Almeida N. História oral e narrativa: tempo, memória e identidade. História Oral, 6, 2005.

ESPINDOLA, Haruf Salmen. Sertão do Rio Doce. Bauru, SP: EDUSC, 2005.

FERNANDES, Duval Magalhães; RIGOTTI, José Irineu Rangel. Os Brasileiros na Europa: notas introdutórias. In: CONFERÊNCIA SOBRE AS COMUNIDADES BRASILEIRAS NO EXTERIOR - "BRASILEIROS NO MUNDO", 1, 2009, Brasília. Anais do ... Brasília, Fundação Alexandre Gusmão, 2009. 
HAESBAERT, Rogério. Identidades Territoriais. In: CORRÊA, Roberto Lobato e ROSENDAHL, Zeny (Orgs). Manifestações da Cultura no Espaço. Rio de Janeiro: UERJ, 1999.

HALBWACHS, Maurice. A memória coletiva. São Paulo: Vértice, 1990.

INFORMATIVO da Prefeitura Municipal de Santa Rita do Itueto "Compromisso com o Agricultor". Santa Rita do Itueto. 2006.

MASSEY, Douglas Steven; ARANGO, Joaquin; GRAEME, Hugo; KOUAOUCI, Ali; PELLEGRINO, Adela; TAYLOR, J. Edward. Theories of international migration: a review and appraisal. Population and Development Review, New York, v. 19, n. 3, p. 431-466, 1993.

MONTEIRO, Norma de Góes. Imigração e Colonização em Minas 1889-1930. Belo Horizonte/Rio de Janeiro: Editora Itatiaia, 1994 (vol. 188).

NICOLI, Sandra; SIQUEIRA, Siqueira. Microrregião de Aimorés: território de imigração italiana e emigração de seus descendentes. In: GUEDES, Gilvan Ramalho; OJIMA, Ricardo (org.). Território: mobilidade populacional: ambiente. Governador Valadares: Editora Univale, 2012.

NICOLI, Sandra, GENOVEZ, Patrícia Falco, SIQUEIRA, Sueli. Migração, Memória e Território: os descendentes de imigrantes italianos da Microrregião de Aimorés/MG. Revista História \& Perspectivas. Dossiê: História do Crime, da polícia e da justiça criminal, v. 26, nº 49, 2013.

NICOLI, Sandra. I/Emigração em Itueta e Santa Rita do Itueto: a chegada dos nonos e a partida de seus descendentes para o norte da Itália. Dissertação (Mestrado em Gestão Integrada do Território). Programa de Pós-Graduação Stricto Sensu em Gestão Integrada do Território, Universidade Vale do Rio Doce, Governador Valadares, 2014. 
$|24|$

Os descendentes de imigrantes italianos...

NICOLI, Sandra. Migração e Retorno: os descendentes de italianos em Minas Gerais/Brasil. In: CONGRESSO INTERNACIONAL - CIÊNCIAS, TECNOLOGIAS Y CULTURAS, 4, 2015, Santiago (Chile). Anais do ... Santiago, USACH, 2015.

PERALTA, Elsa. Abordagens teóricas aos estudos da memória social: uma resenha crítica. Arquivos da Memória. N. 2, 2007.

POLLAK, Michael. Memória e Identidade Social. Estudos Históricos. Rio de Janeiro, v.5, n.10, 1992.

REZENDE, Marcos; ÁLVARES, Ricardo. Itueta: Passado e Futuro. In: REZENDE, Marcos; ÁlVARES, Ricardo (Orgs.). Era Tudo Mata: o processo de colonização do Médio Rio Doce e a formação dos municípios de Aimorés, Itueta e Resplendor. Belo Horizonte, MG: Consórcio da Hidrelétrica de Aimorés, 2009.

SANTOS, Miriam de Oliveira.; ZANINI, Maria Catarina Chitolina. Memórias compartilhadas e comunidades imaginadas: os italianos al estero e suas relações com a emigração contemporânea para a Itália. In: ENCONTRO NACIONAL DE HISTORIA ORAL, 11, 2012, Rio de Janeiro. Anais do ... Rio de Janeiro, Associação Brasileira de História Oral (ABHO), 2012.

SANTOS, Reinaldo Onofre; BARBIERE, Alisson Flávio. Reflexões sobre população, migrações e planejamento regional para o desenvolvimento. In: GUEDES, Gilvan Ramalho; OJIMA, Ricardo (org.). Território: mobilidade populacional: ambiente. Governador Valadares: Editora Univale, 2012.

SAYAD, Abdelmalek. A imigração ou os paradoxos da alteridade. São Paulo: EDUSP, 1998.

SAYAD, Abdelmalek. O retorno: elemento constitutivo da condição do migrante. Travessia, v. 13, n. esp., 2000, p. 7-32, jan.

SAYAD, Abdelmalek. La doble ausencia: De las ilusiones del emigrado a los padecimentos del inmigrado. Barcelona: Anthropos, 2010. 
SAQUET, Marcos Aurélio. Abordagens e concepções de território. 2. edição. São Paulo: Expressão Popular, 2010.

SIQUEIRA, Sueli. Sonhos, sucesso e frustrações na emigração de retorno: Brasil/Estados Unidos. Belo Horizonte: Argvmentvm, 2009.

SIQUEIRA, Sueli; NICOLI, Sandra; SANTOS, Mauro Augusto dos. Os italianos e seus descendentes no Vale do Rio Doce, em Minas Gerais: a chegada dos italianos e a emigração dos descendentes para Itália. In: BENEDUZI, Luís Fernando; ASSIS, Gláucia de Oliveira (Org.). Narrativas de Gênero - Relatos de História Oral: experiências de ítalo-brasileiros na Itália Contemporânea. Vitória: EDUFES, 2014, v.1, p. 191-216.

SIQUEIRA, Sueli. História das migrações da Região de Governador Valadares-MG para os Estados Unidos. In: BÓGUS, Lúcia e BAENINGER, Rosana. A nova face da emigração internacional no Brasil. São Paulo: Educ, 2018, cap. 6, p. 129-148.

SOUZA, Stanley Savoretti. Passeggeri de um sogno: o vapor Montevideo, imigração Italiana em Minas Gerais. Belo Horizonte: adi edições, 2019.

TEDESCO, João Carlos. Do Brasil à Itália: processos históricos e culturais de uma nova realidade emigratória. Travessia - Revista do Migrante. São Paulo, 2010. v. 67, p. 21-36.

TILLY, Charles. Transplanted Networks. In: YANS-McLAUGHLIN, V. (ed.). Immigration Reconsidered: History, Sociology and Politics. Nova Iorque: Oxford University Press, 1990, p. 79-95.

TRENTO, Ângelo. Do outro lado do Atlântico: um século de imigração italiana no Brasil. São Paulo: Nobel, 1989.

ZANINI, Maria Catarina Chitolina. HERÉDIA, Vania Beatriz Merlotti. Migrantes em terra estrangeira: retorno à terra dos antepassados. In: ASSIS, Gláucia de Oliveira; BENEDUZI, Luís Fernando (Org.). Os pequenos pontos de partida: novos e(i) migrantes rumo à Itália no século XXI. 1ed. Curitiba/PR: CRV, 2014, v. 1, p. 131-145. 